\title{
A MATEMÁTICA DO ENSINO E O ENSINO DE MATEMÁTICA: AS FRAÇÕES NOS PRIMEIROS ANOS ESCOLARES, SEGUNDA METADE DO SÉCULO XIX
}

Las matemáticas de la enseñanza y la enseñanza de las matemáticas: fracciones en la escuela primaria, segunda mitad del siglo XIX

Mathematics from teaching and mathematics teaching: fractions in primary school, second balf of the igth century

Wagner RodRIgues VALENTE

Universidad Federal de São Paulo

Correo-e: wagner.valente@unifesp.br

Recepción: Is de octubre de 2020. Envío a informantes: 17 de octubre de 2020 Aceptación definitiva: 22 de noviembre de 2020

Resumo: Este texto divulga resultados de pesquisas que vêm sendo desenvolvidas no âmbito de um grupo de investigadores em torno de projetos coletivos de trabalho. Tais projetos têm por interesse analisar historicamente as mudanças no saber profissional do professor que ensina matemática nos primeiros anos escolares. Em específico, para este artigo, privilegiou-se o estudo pontual sobre as frações. Utiliza-se como aparato teórico-metodológico os estudos culturais, em particular, mobiliza-se o conceito de cultura escolar, considerando a escola como produtora de saberes no seio dessa cultura. A partir dessa referência explicitam-se as diferenças entre «matemática do ensino» e «ensino de matemática». A pergunta norteadora que conduz o artigo pode ser enunciada do seguinte modo: Como caracterizar a matemática do ensino de frações na segunda metade do século XIX? Os resultados mostram a organização de uma matemática do ensino de frações que se altera em razão das necessidades de escolarização do sistema métrico decimal.

Palavras-CHAve: frações; cultura escolar; matemática do ensino; ensino de matemática. 
Resumen: Este texto socializa los resultados de investigaciones que se han desarrollado dentro de un grupo de investigadores en torno a proyectos de trabajo colectivo. Estos proyectos están interesados en analizar históricamente los cambios en el conocimiento profesional de los profesores que enseñan matemáticas en la escuela primaria. En particular, para este artículo, se privilegió el estudio específico sobre fracciones. Los estudios culturales se utilizan como aparato teórico-metodológico, en particular, se moviliza el concepto de cultura escolar, considerando la escuela como productora de conocimiento dentro de esta cultura. Desde este posicionamiento teórico, se explicitan las diferencias entre «matemáticas de la enseñanza» y «enseñanza de las matemáticas». La pregunta orientadora que conduce el artículo se puede plantear de la siguiente manera: ¿Cómo caracterizar las matemáticas de la enseñanza de fracciones en la segunda mitad del siglo XIX? Los resultados muestran la organización de una matemática a partir de la enseñanza de fracciones que cambia debido a las necesidades de escolarización del sistema métrico decimal.

Palabras clave: fracciones; cultura escolar; matemáticas desde la enseñanza; enseñanza de las matemáticas.

AвsтRAct: This text socializes research results that have been developed within a group of researchers around collective work projects. Such projects are interested in historically analyzing changes in the professional knowledge of teachers who teach mathematics in primary school. In particular, for this article, the specific study on fractions was privileged. Cultural studies are used as a theoreticalmethodological apparatus, in particular, the concept of school culture is mobilized, considering the school as a producer of knowledge within this culture. From this theoretical positioning, the differences between «mathematics from teaching» and «teaching of mathematics» are made explicit. The guiding question that leads the article can be stated as follows: How to characterize the mathematics of teaching fractions in the second half of the inth century? The results show the organization of a mathematics from teaching of fractions that changes due to the schooling needs of the decimal metric system.

KEY WORDs: fractions; school culture; mathematics from teaching; teaching of mathematics.

\section{Considerações iniciais}

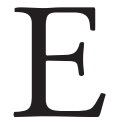

STE TEXTO FOI ELABORADO com a intenção de divulgar resultados de pesquisas que vêm sendo realizadas pelo GHEMAT Brasil - Grupo Associado de Estudos e Pesquisas em História da Educação Matemática (ghematbrasil.com), associação sem fins lucrativos, que congrega mais de vinte estados brasileiros, por meio de grupos de pesquisas alocados em diferentes programas de pós-graduação de diversas instituições de ensino superior. O Grupo tem seu modus operandi dado pela articulação de dezenas de investigadores em torno de projetos coletivos de trabalho. No momento atual, tais projetos abordam estudos 
históricos sobre o ensino e a formação de professores de matemática, tendo vista a caracterização do saber profissional da docência ${ }^{1}$.

O presente artigo concentra atenção especificamente na matemática ensinada nos primeiros anos escolares. Buscar-se-á mostrar que, em acordo com estudos da cultura escolar, a matemática presente no ensino resulta de processos e dinâmicas historicamente elaborados, algo diverso e não idêntico às demandas dos campos disciplinares científicos. $\mathrm{O}$ artigo concentra atenção no tema frações. Como caracterizar a matemática do ensino de frações na segunda metade do século XIX? Tal interrogação norteia o desenvolvimento deste artigo.

\section{Frações: um tema polêmico}

Em texto síntese sobre o ensino de frações, a pesquisadora Paula Resende Adelino dá a conhecer diferentes propostas relativamente à presença desse conteúdo nos primeiros anos escolares:

Há aqueles que defendem que o ensino das frações deve preceder o ensino dos números decimais; há os que defendem justamente o contrário, primeiro números decimais e, posteriormente, frações; existem os que defendem o ensino simultâneo das frações e dos números decimais; e, por último, talvez os mais radicais, aqueles que afirmam que não se deve ensinar frações, apenas números decimais (Adelino, 20I4: 3).

Diante dessas diferentes propostas, vamos considerar a mais radical e refletir sobre ela: a retirada do ensino de frações. As demais, de algum modo, mantém este tema presente no ensino, apenas indicando sequências diferentes na marcha do trabalho pedagógico: antes, depois ou ao mesmo tempo que as lições sobre números decimais.

Não se deve ensinar frações! A justificativa evocada para a retirada do ensino de frações, por um dos autores mencionados por Adelino (20I4), é a de que

Não é provável que uma argumentação racional venha a demover alguém da crença na eficácia e necessidade do ensino de frações nas séries iniciais; mas talvez seja possível fazer ver que não há base racional, nem científica, nem histórica, nem filosófica que possa sustentar a permanência das frações nos currículos escolares... Elas permanecem, mas não devido a argumentos ou a algum imperativo racional. Elas permanecem à força, por inércia, por medo, por ignorância ou desconhecimento (Vianna apud Adelino, 2014).

Aqui, cabe citar dois projetos coletivos em vigência. Um deles, intitulado «Os experts e a sistematização da matemática no ensino e na formação de professores» (Projeto Edital Universal $\mathrm{CNPq}$, 20I8-20I2); o segundo, denominado «A matemática na formação de professores e no ensino: processos e dinâmicas de produção de um saber profissional, i890-1990" (Projeto Temático FAPESP, 2017-2022). 
A MATEMÁTICA DO ENSINO E O ENSINO DE MATEMÁTICA: AS FRAÇÕES NOS PRIMEIROS ANOS ESCOLARES, SEGUNDA METADE DO SÉCULO XIX WAGNER RODRIGUES VALENTE

As razões evocadas para a retirar as frações do ensino explicita, na verdade, uma concepção sobre as dinâmicas e processos que estão presentes no cotidiano escolar. Apesar da radical postura de advogar a retirada das frações, algo que seria uma mudança, supostamente um avanço, a proposta alinha-se a um modo tradicional e conservador de análise do funcionamento do dia-a-dia escolar. Retirar as frações não será possível. Em síntese, segundo o autor, pois a escola é lócus da inércia para mudanças, do medo às alterações, da ignorância ou desconhecimento da racionalidade que deveria presidir o ensino de matemática.

Uma análise muito diversa pode ser realizada numa outra perspectiva. Nela, a escola não deve ser vista "do lado de fora», como parece ser esse o caso da proposta de retirada das frações do currículo escolar. Analisar a escola internamente, buscando compreender a teia de significados presentes no cotidiano escolar, refere-se a perspectiva que se alinha a uma análise cultural das instituições. Em específico, tal visão pondera que a escola tem uma cultura própria, forjada ao longo do tempo. Há, neste caso, que se levar em conta uma cultura escolar ${ }^{2}$. No âmbito dessa cultura, deverá o pesquisador se postar para compreender as dinâmicas e processos que ocorrem no cotidiano das aulas. E essa cultura escolar produz saberes que, ao longo tempo, constituem a cultura transmitida pela escola, uma cultura de passagem à cultura do mundo adulto.

Assim, ao pesquisador da cultura escolar cabe tratar menos do ensino de algo de fora para dentro da escola e mais do que a escola, ao longo do tempo, elabora para ser ensinado. Em nosso caso, concentramo-nos na matemática do ensino, ao invés de discutir o ensino de matemática...

\section{Ensino de matemática e matemática do ensino}

Os estudos históricos de André Chervel mostram como, ao longo do tempo, a escola foi elaborando os saberes em forma de disciplinas escolares. Esse é um resultado que contradiz a ideia de que à escola cabe tão somente o papel de reproduzir os saberes elaborados fora dela. E, mais, coloca em xeque a avaliação de que o meio escolar, a cultura escolar, é «lugar da inércia para mudanças, do medo às alterações, da ignorância ou desconhecimento da racionalidade».

No que toca aos saberes professados na escola, os estudos de Chervel dão contribuição relevante, pois contrapõem-se à ideia vigente de que à escola é instituição reprodutora dos saberes vindos dos campos disciplinares científicos. Desse modo, os estudos de Chervel permitiram estabelecer diferenças epistemológicas

\footnotetext{
2 Um dos primeiros teóricos a sistematizar o conceito de «cultura escolar» foi o historiador Dominique Julia. Para esse autor, podemos tal caracterizar tal cultura como «um conjunto de normas que definem conhecimentos a ensinar e condutas a inculcar, e um conjunto de práticas que permitem a transmissão desses conhecimentos e a incorporação desses comportamentos; normas e práticas coordenadas a finalidades que podem variar segundo as épocas (finalidades religiosas, sociopolíticas ou simplesmente de socialização)» (Julia, 2ooI, p. ıo).
} 
fundamentais entre uma disciplina científica e uma disciplina escolar (Chervel, I990).

Assim, constitui perspectiva muito diversa, analisar historicamente o desenvolvimento dos saberes que vêm sendo elaborados no seio da cultura escolar, comparativamente à ideia de que cabe às instituições de ensino tão somente o lugar de transmissão de saberes elaborados alhures. Tal perspectiva nos autoriza a considerar a existência de uma matemática do ensino, algo distinto de ensino da matemática. A primeira, produção histórica da cultura escolar; a segunda expressão, ligada à ideia de transmissão da produção do campo disciplinar matemático para o nível escolar.

Tradicionalmente, o uso da expressão «ensino de matemática» envolve a perspectiva de análise das relações que deveriam ser estabelecidas entre o campo disciplinar matemático, os saberes matemáticos, e a sua transmissão para crianças e adolescentes. Em última análise, está posta como premissa, neste caso, que o papel da escola é o da transmissão dos saberes do campo disciplinar. Em específico, do campo disciplinar matemático. Por certo, nesta perspectiva, a matemática do campo disciplinar não é considerada idêntica àquela presente no meio escolar. Mas, as diferenças evocadas levam em conta tão somente aspectos de sua didatização. Cabe, neste caso, a organização do saber matemático, em seus elementos, para ser transmitido aos alunos. A diferença que se estabelece entre a matemática do campo disciplinar e a matemática ensinada na escola é considerada de nível: de uma matemática mais avançada do ensino superior àquela elementar da escola básica. Tal situação é bem adequada à crítica que Chervel (1990) realiza, indicando que o desafio do campo disciplinar para ser transmitido lança mão de ideia redutora da pedagogia: ela é vista como elemento lubrificante a permitir que na escola seja possível a transmissão do saberes dos campos disciplinares matemáticos, científicos.

De modo distinto da perspectiva dada pelo ensino de matemática, a matemática do ensino interessa-se de modo prioritário por questões epistemológicas. Analisa processos e dinâmicas de constituições dos saberes escolares, da matemática presente na escola, da matemática do ensino. Como se caracteriza essa matemática? Ou de modo mais preciso, e indo ao encontro dos objetivos deste artigo: Como caracterizar a matemática do ensino de frações na segunda metade do século XIX? Esta questão, com se disse anteriormente, norteia este estudo, e buscará ser respondida com o uso, sobretudo, de livros didáticos.

\section{Livros didáticos como documentos para estudo da matemática do ensino}

Em texto publicado já há algum tempo, analisamos o uso de livros didáticos como material empírico a ser transformado em fontes para a pesquisa em história da educação matemática. Caberia retomar aqui algumas reflexões elaboradas àquela altura. 
Em realidade, o que mais comumente se tem feito, nas pesquisas com livros didáticos de matemática, é o seu uso para estudo de uma temática particular: um determinado tema, assunto ou item de conteúdo matemático torna-se objeto de estudo histórico, através de livros didáticos de outros tempos escolares. Ora é o estudo do Teorema de Pitágoras, ora o de Thales; ou, ainda, aspectos do desenvolvimento de demonstrações ou o tratamento dos números irracionais, dentre muitos outros interesses temáticos. A partir da escolha do tema, são feitas as leituras de sua abordagem nos livros didáticos. O problema que muitas vezes decorre desse ponto de partida está ligado ao que poderíamos chamar de «fascínio pelo conteúdo interno do livro didático de matemática». Trata-se de algo que parece inescapável no caso da educação matemática. E o pesquisador, mais do que noutras áreas, tudo leva a crer, tende a isolar esse conteúdo matemático de uma infinidade de outros elementos determinantes e explicativos da obra. Enfileirar uma série de livros didáticos de épocas históricas diferentes que tratam de um mesmo conteúdo específico de matemática e compará-las entre si é ato comum ao pesquisador iniciante. Mais problemáticas, ainda, são as conclusões tiradas dessa comparação: ao invés de ver no presente as marcas do passado, não raro busca ver, no passado, determinações do presente, como alerta um famoso historiador. Então, como ultrapassar essas análises preliminares baseadas na comparação simples de conteúdos matemáticos, de modo a transformar os livros didáticos de matemática em fontes para a pesquisa histórica? (Valente, 2008: I44-I45).

Tais reflexões pretendem contribuir com a análise dos livros didáticos como um artefato cultural da escola, um elemento da cultura escolar. De outra parte, utilizar livros didáticos não representa garantia de que os estudos estariam situados no nível da cultura escolar, no âmbito das produções escolares. Ressalta-se que a análise de um dado assunto em matemática, nos livros didáticos, acaba levando muitos pesquisadores a permanecer com o olhar exterior à cultura escolar. $\mathrm{O}$ anacronismo implica no transporte de produtos culturais da escola, da cultura escolar, para outra ambiência, utilizando critérios alheios àqueles que permitiriam melhor significar essa produção, a dos livros didáticos. Desse modo, permanece o desafio de caracterizar a matemática do ensino, fruto da cultura escolar, considerando um dado tema dessa matemática, por meio de livros didáticos. Assim, repõe-se a questão: Como caracterizar a matemática do ensino de frações na segunda metade do século XIX? E, ainda, como elaborar essa caracterização sem que seja considerada uma perspectiva externalista, alheia à cultura escolar?

As pesquisas que vêm sendo desenvolvidas em projetos coletivos do GHEMAT Brasil vêm contribuindo com a análise da matemática do ensino, de sua caracterização, em diferentes épocas da História da Educação, utilizando livros didáticos como fontes de pesquisa $a^{3}$. Todavia, até o presente momento, não há estudos mais pontuais, e ao mesmo tempo de maior profundidade, que tomem

3 Citem-se os trabalhos de Oliveira (2017) e Pinheiro (2017). O primeiro caracterizou o que poder-se-ia chamar de aritmética intuitiva, vigente em finais do século xIx e primeiras décadas do século xx. O segundo estudo contribuiu para caracterizar uma aritmética sob medida, fruto de um tempo onde prevalece a psicologia experimental de base estatística, em tempos de uma pedagogia científica. 
um dado tema de ensino, analisando-o no seio de uma matemática do ensino. Dessa maneira, justifica-se a intenção deste presente artigo em considerar um tema específico - neste caso, as frações - analisando-o como integrante de uma matemática do ensino, vigente numa dada época.

A análise dos livros didáticos de uma dada época, consideramos, possibilita caracterizar a matemática do ensino de frações. Tal análise irá ancorar-se em elementos próprios dos saberes mobilizados na escola. Elementos próprios da cultura escolar. Os estudos preliminares que vêm sendo realizados até o presente momento apontam serem importantes: a sequência, o significado, a graduação e os exercícios e problemas em que um dado tema do ensino está enredado (Valente, 2020).

Considerando o tema das frações, analisaremos como se apresentam tais elementos nos livros didáticos.

Um primeiro elemento mencionado refere-se à sequência indicada para a matemática do ensino de frações, postas nos livros didáticos. Entende-se por sequência o lugar ocupado pelas frações no conjunto dos temas da aritmética. Assim, caberia verificar, para uma dada obra, como o autor introduz as frações, vale dizer, após que temas tratados? E, ainda, o que segue o ensino de frações numa dada aritmética posta num livro didático?

Um outro elemento que as pesquisas que vêm sendo levadas pelo GHEMAT Brasil apontam como importante para análise da matemática do ensino refere-se ao significado dado às frações no texto escolar: como são definidas as frações? Isto é, como o texto comunica o significado das frações ao aluno? Que ideia primeira deve o aluno ter de frações?

Segue-se, na análise dos livros didáticos, a graduação como mais um elemento distintivo da matemática do ensino, da matemática do ensino de frações: qual o passo-a-passo deverá ser seguido pelo professor para tratar as frações? Assim, no conjunto dos escritos do livro didático, que temas são encadeados para o entendimento da ideia de frações?

Por fim, mas não menos importante, tem-se a análise dos exercícios e problemas que remetem às expectativas de respostas esperadas pelos professores relativamente ao que ensinaram sobre frações para seus alunos.

Sequência, significado, graduação e exercícios/problemas constituem categorias de análise utilizadas a partir de estudos, ainda em desenvolvimento nos projetos coletivos do GHEMAT Brasil. Tais elementos permitem que seja realizada uma espécie de anatomia epistemológica da matemática do ensino. Por certo, uma epistemologia dos saberes escolares. A partir dessa anatomia da matemática do ensino, tem-se uma possibilidade caracterizar a matemática do ensino de um dado tempo escolar, em termos de um tema específico, frações, por exemplo.

\section{A matemática tradicional do ensino de frações}

A História da Educação brasileira mostra-nos a lenta organização de escolas para ler, escrever e contar: as escolas ditas de primeiras letras. Também demorada 
é a ampliação da escolaridade obrigatória. Recorde-se que até o início da década de 1970, ao Estado cabia a obrigação de tão somente ofertar quatro anos de escola: o curso primário. Também recorrendo aos historiadores da educação, tem-se que esse panorama começa a sofrer alterações na passagem do Império para a República, onde os políticos e autoridades passam a ver na instituição escolar a referência para modernizar o país (Souza, 2009).

O marco inicial de constituição das escolas de ensino primário é dada pela Lei de Is de outubro de I827. A produção de obras didáticas de aritmética para o curso primário, de modo mais intenso, começa a ocorrer em princípios da segunda metade do século xix (Valente, 2006). Para este texto, escolhemos duas obras que nos pareceram bastante significativas, devido a número de edições que tiveram, a partir da segunda metade do século xix: o livro de Ascanio Ferraz da Motta, intitulado Pequeno Curso de Arithmetica para uso das escola primarias e a obra de José Theodoro de Souza Lobo, Primeira Arithmetica para Meninos.

Motta escreve uma das primeiras obras do período, em I859. Na capa do livro tem-se os dados profissionais desse autor: «Director do Collegio Normal, Membro Effectivo, Correspondente e Honorario de Diversas Sociedades Scientificas e Litterarias, Nacionais e Estrangeiras etc.». As informações das páginas iniciais indicam que o livro, como muitas dessas primeiras obras, foi impresso em Paris, por B. L. Garnier, Editor. A obra teve, pelo menos, três edições que abarcaram toda a segunda metade do século XIX. A primeira em I859, a segunda em I874 e a última em I892. Tais edições mantiveram sempre o mesmo texto (Costa e Almouloud, 20I2).

Figura I. Capa do livro

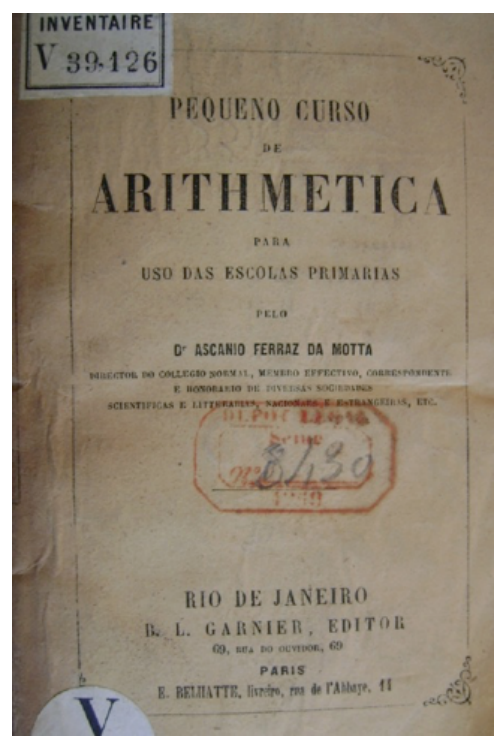

Fonte: https://repositorio.ufsc.br/handle/I23456789/100350. 
Um outro livro didático, igualmente importante para o período que está sendo considerado neste texto - segunda metade do século XIX - refere-se à obra de Souza Lobo: Primeira Arithmetica para Meninos.

José Theodoro de Souza Lobo, natural de Porto Alegre, Rio Grande do Sul, nasceu em 7 de janeiro de 1846 e faleceu na mesma cidade, em 9 de agosto de 1913. Foi professor de Matemática da Escola Normal de Porto Alegre, escritor de obras literárias e inspetor da instrução pública e também proprietário de um colégio. Estudou na Escola Central do Rio de Janeiro, instituição que precedeu à criação da Escola Politécnica, onde recebeu o diploma de engenheiro geógrafo (Pais, 20IO: I3I).

A primeira edição da Primeira Arithmetica veio à luz em I874. A obra constitui-se num verdadeiro best-seller. Para que se possa ter ideia, o livro teve 4I edições, sendo publicado até 1933 (Pfromm Neto et al., 1974).

Figura iI: Capa do livro

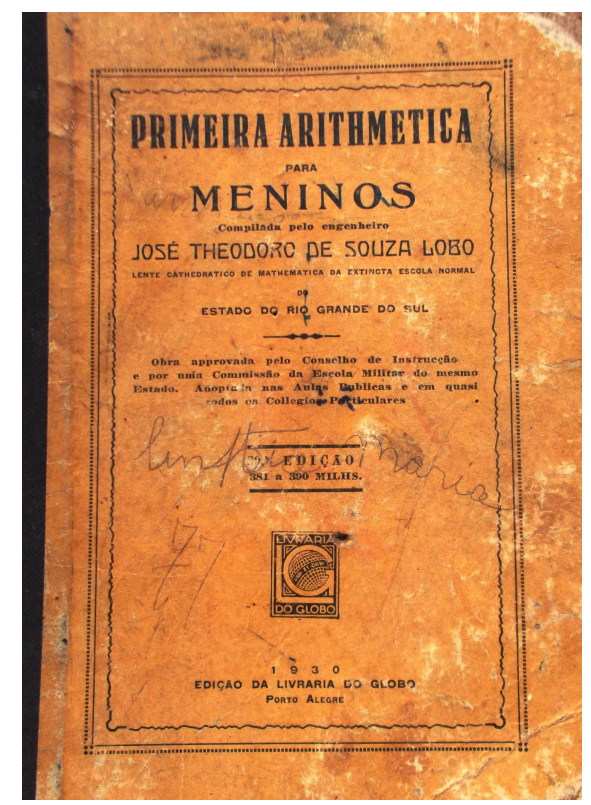

Fonte: https://repositorio.ufsc.br/handle/123456789/100100.

$\mathrm{Na}$ análise de como as obras tratam as frações é possível observar duas sequências diferentes de inserção das frações na aritmética. A primeira delas, lida na obra de Motta (1859) mostra-nos a sequência Operações Fundamentais, Frações Ordinárias, Frações Decimais e Sistema Métrico. A segunda, de Souza Lobo, promove uma inversão: Operações Fundamentais, Frações Decimais, Sistema Métrico Decimal e Frações Ordinárias. 
$\mathrm{Na}$ busca de explicações relativamente a essa mudança da matemática para o ensino de frações, em termos de diferentes sequências, não é possível encontrar nas próprias obras justificativas para o fato. De outra parte, cotejando os livros didáticos com manuais pedagógicos, encontram-se argumentos que orientam o trabalho do professor relativamente à conveniência de uma dada sequência. Neste caso, como exemplo, cite-se o manual Curso Pratico de Pedagogia - destinado aos alunos das escolas normais primarias, aspirantes ao magistério e aos professores em exercício, obra clássica, traduzida e muito utilizada no Brasil, escrita pelo francês Daligualt, publicada em I870 (Figura III). A leitura do manual informa o professor sobre a sequência que deveria ser utilizada nas aulas relativamente às frações ordinárias e os números decimais.

\section{FIgURA III: capa de livro}

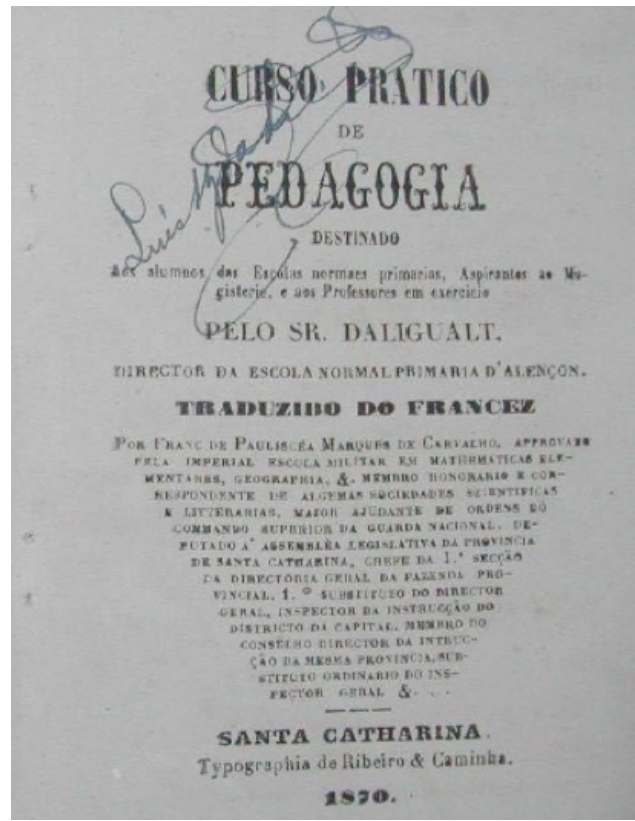

Fonte: https://repositorio.ufsc.br/handle/I23456789/179927.

O manual orienta os professores sobre a sequência em que devem ser ensinadas as frações: antes dos números decimais, logo após as operações fundamentais. Diz o livro:

Colocamos imediatamente depois das quatro regras [...] o estudo das frações ordinárias, porque o conhecimento desta parte da Aritmética é quase indispensável para a solução pelo método da unidade dos problemas relativos a regras de três, de juros etc. (1870: 233). 
Assim, a justificativa para a sequência que inclui as frações ordinárias antes dos números decimais está ligada ao uso do chamado «método da unidade» ou método da redução à unidade, em que nos problemas envolvendo regra de três e juros, tem-se o cálculo de um valor para uma unidade de alguma grandeza conhecida, que será estendido para quantas os problemas desejar calcular. Assim, as orientações que o professor deveria seguir relativamente ao ensino de frações indicam que é conveniente, depois de ensinadas as quatro operações fundamentais logo sejam tratadas as frações ordinárias, pois elas são fundamentais para resolver problemas. E a resolução dos problemas envolve a redução à unidade. Assim, ao invés de tratar os problemas de modo direto com o uso do conceito de proporcionalidade, o professor deveria levar os alunos a calcularem, a partir do valor de uma unidade de uma grandeza conhecida, as unidades de outra grandeza desconhecida solicitadas pelo problema.

De outra parte, a busca de argumentos para a inversão dessa sequência, noutras obras, como as de Souza Lobo, encontra justificativa para a sua adoção, a partir de Lei brasileira datada de 1862 (Lei n. I.I57 de 26 de junho), do sistema métrico decimal. Pela lei, as escolas teriam um prazo de dez para incluírem no ensino os cálculos utilizando o novo sistema. Assim, os autores mobilizaram-se para adiantar o estudo dos números decimais e suas operações, de modo a garantir em sequência o estudo do sistema métrico decimal.

Um outro elemento relativamente à matemática do ensino de frações, como mencionado anteriormente, refere-se ao significado dados às frações no momento inicial de seu ensino. E, veremos, tal significado também varia, nessa segunda metade do século XIx. A depender da sequência adotada para o ensino, as frações assumem diferentes significados.

Considerando-se a sequência operações-frações-decimais, as frações significam operadores que dividem coisas da vida cotidiana em partes iguais, das quais deseja-se tomar algumas delas: «As frações se formam pela divisão da unidade em partes iguais» (Motta, 1859: 32). Já para a sequência operações-decimais-frações, as frações constituem razões entre dois números para uso em problemas de mudanças de sistemas de medidas: «Frações ordinárias são partes da unidade, menores do que ela, em uma razão qualquer» (Lobo, 1930/1874: IIO).

Relativamente à graduação, ela também é afetada para as diferentes sequências. Para a sequência operações-frações-decimais, a ordem de graduação dos assuntos relativos às frações é dada por: definição de fração ordinária-nomenclaturapropriedades-denominador comum-operações com frações. Nesta sequência há necessidade de enunciar propriedades e discutir previamente a redução ao mesmo denominador das frações para, em seguida, promover as operações. No caso da sequência operações-decimais-frações a ordem graduada dos assuntos é dada por: definição de fração decimal-nomenclatura-operações-sistema métrico decimaldivisores dos números-operações com frações. Para este segundo caso, o trabalho com números decimais ao princípio remete à semelhança de trato das operações com algoritmos vistos para os números naturais (inteiros): «As frações decimais representam-se como números inteiros» (Lobo, 1930/1874). 
Por fim, o que os professores esperam de seus alunos com o ensino de frações? A análise dos exercícios e problemas também mostra alguma variação nessas expectativas. Para o caso das frações antecedendo os decimais, espera-se que os alunos saibam resolver cálculos de partição, considerando sempre o valor de uma parte, já que todas devem ser iguais. A partir disso, espera-se que o aluno saiba calcular o número associado a quantas sejam as partes solicitadas num exercício ou problema que, supostamente, é importante para a sua vida fora da escola: «Um homem morrendo legou os $2 / 5$ de sua fortuna a 4 parentes; quanto tocou a cada um?» (Motta, I859).

De outro lado, tendo em vista o ensino dos decimais em primeiro lugar, face às frações ordinárias, há necessidade de cálculos entre os sistemas antigos e o sistema decimal, além de cálculos no interior do próprio sistema decimal: «Seis hectolitros de certa mercadoria custaram 25\$500; quanto custarão Io litros?» (Lobo, 1930/1874).

A matemática do ensino de frações neste período primeiro da história da educação, compreendendo desde a Independência do Brasil (1822) até décadas finais do século XIX mostra-se por meio do que costumeiramente é denominado «ensino tradicional». Um ensino tido por verbalístico, centrado no professor, cuja tarefa é, no caso da matemática dos primeiros anos, levar os alunos a exercitarem o cálculo numérico. $\mathrm{O}$ ensino prevê que bem exercitado nos cálculos, os egressos farão uso deles na vida cotidiana. $\mathrm{Na}$ orientação aos professores tem-se que:

Para fazer com que os alunos adquiram o conhecimento prático do cálculo, o professor deve lhes dar sobre cada uma das operações numerosos problemas a resolver. Mas, sobretudo, no estudo das frações é que deve multiplicar as aplicações (Daligault, I870: 234).

Assim, por meio da fala professor, a ordenar a realização dos exercícios com frações, numerosos, buscar-se-ão aplicações que possam, na vida cotidiana, serem úteis. Manejando os problemas e exercícios elaborados no âmbito mesmo do ensino de aritmética, forjados como treino, hoje vistos como algo longínquo dos reais problemas cotidianos [ «Seis hectolitros de certa mercadoria custaram $25 \$ 500$; quanto custarão Io litros?»], os alunos estariam aptos para resolverem problemas existentes na vida real.

\section{Considerações finais}

Os estudos que vêm sendo desenvolvidos por uma verdadeira comunidade de pesquisadores sob a égide do GHEMAT Brasil envolvem investigações sobre uma mesma temática, abordada em várias dimensões. De outra parte, o foco central dessas pesquisas liga-se aos saberes. Neste texto, priorizamos tratar dos saberes envolvidos no ensino. Há várias outras dimensões da pesquisa, dentre elas, estudos sobre os saberes envolvidos na formação de professores, as relações que 
se estabelecem ao longo do tempo entre saberes do ensino e saberes da formações de professores etc. Como mencionado, este texto tratou dos saberes presentes no ensino. A matemática do ensino, a matemática do ensino de frações na segunda metade do século XIx. Como compreender o modo como foram sistematizados os saberes presentes no ensino de matemática do curso primário? Ou repondo a questão norteadora deste texto: Como caracterizar a matemática do ensino de frações na segunda metade do século XIX?

A resposta à questão envolve um distanciamento relativo do campo disciplinar matemático. Liga-se aos processos e dinâmicas de produção de saberes, ao longo do tempo pela escola. Por certo, a cultura escolar, como qualquer cultura, mantém relações com outras culturas, diferentes dela. No limite, a cultura que se volta a si própria, não se relacionando com outras culturas, tende a desaparecer. A cultura escolar mantém relações com a cultura geral que a cerca, levando em consideração a cada tempo as diferentes finalidades atribuídas à escola: política, social, religiosa etc. A cultura escolar mantém relações mais diretas com a cultura universitária, por meio dos diferentes campos disciplinares. E essas relações são fundamentais para as discussões que envolvem os saberes presentes na escola. Essas relações também modificam-se ao longo do tempo. Um dos resultados dessas relações interculturais, de modo a possibilitar que o ensino ocorra, refere-se à produção de saberes para o ensino. Secretando saberes ao longo do tempo, a cultura escolar mostra-se criativa e define, num dado tempo, o que ensinar, por que ensinar, como ensinar. Em específico, a análise histórica intenta revelar como tais processos e dinâmicas ocorreram.

A matemática do ensino de frações na segunda metade do século XIX revela mudanças relativamente à opção dos ensinos de frações ordinárias e frações decimais (números decimais). Buscou-se mostrar que a matemática do ensino de frações, a depender de uma dada finalidade colocada para a escola, reconfigurase. A obrigatoriedade de inclusão do novo sistema métrico decimal, como se viu, reconfigurou a matemática do ensino de frações.

Em síntese, é possível tomar a cultura escolar da segunda metade do século XIX, caracterizando-a, no que toca a matemática do ensino, pelo binômio verboutilidade. Assim, o que poderemos chamar de matemática tradicional do ensino de frações, na antiga escola de primeiras letras, ampara-se numa organização de estudos justificada pela retórica da utilidade da matemática do ensino fora da escola. Tal retórica advoga que aquilo que o mestre ensina possa ter relação com as demandas da vida cotidiana: o verbo primeiro, na escola; depois, a ação, fora dela: frações da escola para o uso na vida.

\section{Referências}

Costa, D. A. e Almouloud, S. A.: «Alguns aspectos da história da aritmética escolar no Brasil (séc. XIX) no ensino elementar». Rev. Prod. Disc. Educ. Matem., São Paulo, v. I, n. I (20I2), pp. 30-52. Disponível em: https://revistas.pucsp.br/index.php/pdemat/article/viewFile/922I/6840. Acesso em: 22/08/2020. 
Oliveira, M. A. D.: A aritmética escolar e o método intuitivo: um novo saber para o curso primário (I870-1920), 28of., Tese (Doutorado em Ciências), Universidade Federal de São Paulo. São Paulo, 20I7. Disponível em <https://repositorio.ufsc.br/handle/I23456789/178956>. Acesso em: 05/05/2020.

Pais, L. C.: «Traços históricos do ensino da aritmética nas últimas décadas do século xix: livros didáticos escritos por José Theodoro de Souza Lobo", RBHM, v. Io, n. 20 (20I0), pp. I27-I46.

Pfromm Netto, S. et al.: O livro na educação, Rio de Janeiro, Primor e Instituto Nacional do Livro, 1974 .

Pinheiro, N. V. L.: A Aritmética sob medida: a matemática em tempos da pedagogia científca, 224f., Tese (Doutorado em Ciências), Guarulhos, Universidade Federal de São Paulo, 2017. Disponível em <https://repositorio.ufsc.br/handle/ı23456789/179942>. Acesso em: $05 / 05 / 2020$.

VALENTE, W. R.: «A aritmética na escola de primeiras letras: os livros de aprender a contar no Brasil do século XIX», Unión, n. 7 (2006), pp. 7I-8I. Disponível em: http://www.fisem.org/ www/union/revistas/2006/7/Union_007_009.pdf. Acesso: 31/08/2020.

VALENTE, W. R.: «Livro didático e educação matemática: uma história inseparável», Zetetiké, I6(2) (2009). https://doi.org/Io.20396/zet.vi6izo.8646894

VALENTE, W. R.: "A pesquisa sobre história do saber profissional do professor que ensina matemática: interrogações metodológicas», Paradigma (Maracay), v. XLI (2020), pp. 900-9II. 